ORIGINAL ARTICLE

\title{
The introduction of solids in relation to asthma and eczema
}

\author{
A Zutavern, E von Mutius, J Harris, P Mills, S Moffatt, C White, P Cullinan
}

Arch Dis Child 2004;89:303-308. doi: 10.1136/adc.2002.025353

See end of article for authors' affiliations ......................

Correspondence to: $\operatorname{Dr} \operatorname{Dr} A$ Zutavern, von Haunersches Kinderspital, Lindwurmstr. 4, 80337 Muenchen, Germany; anne.zutavern@ kk-i.med.uni-muenchen.de

Accepted 3 June 2003
Background: Despite scarce scientific evidence, current feeding guidelines recommend delayed introduction of solids for the prevention of asthma and allergy.

Aims: To explore whether late introduction of solids is protective against the development of asthma, eczema, and atopy.

Methods: A total of 642 children were recruited before birth and followed to the age of $5 \frac{1}{2}$ years. Main outcome measures were: doctor's diagnosis of eczema ever, atopy according to skin prick test results against inhalant allergens, preschool wheezing, transient wheezing, all defined at age 5-51/2 years. Introduction of solids as main exposure measure was assessed retrospectively at age 1 year.

Results: There was no evidence for a protective effect of late introduction of solids for the development of preschool wheezing, transient wheezing, atopy, or eczema. On the contrary, there was a statistically significant increased risk of eczema in relation to late introduction of egg (aOR 1.6, 95\% $\mathrm{Cl} 1.1$ to 2.4) and milk (aOR 1.7, 95\% Cl 1.1 to 2.5). Late introduction of egg was furthermore associated with a nonsignificant increased risk of preschool wheezing (aOR 1.5, 95\% Cl 0.92 to 2.4). There was no statistical evidence of feeding practices playing a different role in the development of asthma and eczema after stratification for parental asthma and atopy status.

Conclusions: Results do not support the recommendations given by present feeding guidelines stating that a delayed introduction of solids is protective against the development of asthma and allergy.
C hildhood wheezing is not a single entity. Different wheezing patterns have been described and have been attributed to different risk factors and to different risks of persistence and progression of these symptoms in adolescence and adulthood. Today transient wheezing is mostly considered a benign disorder that is not likely to persist beyond infancy. Persistent wheezing and late onset wheezing, as described by Martinez et al, have been ascribed a poorer prognosis. ${ }^{1}$ Both conditions have been associated with atopy (often defined as positive skin prick test results) in contrast to transient and no wheezing. ${ }^{1}$

Early allergic sensitisation is seen as an important predictor for the persistence of asthma from childhood into adulthood. ${ }^{1-3}$ Typically, earliest sensitisation occurs against food allergens (cows' milk and hen's egg) as assessed by serum IgE in the first two years of life. ${ }^{45}$ Infants sensitised against these dietary allergens are more likely to develop sensitisation against aero-allergens. ${ }^{4-6}$ Isolated sensitisation to food allergens seldom persists. Asthma and atopic dermatitis in turn are associated with sensitisation against both food and inhalant allergens. ${ }^{67}$ Measures to decrease the risk of food sensitisation such as dietary interventions have been proposed to also reduce the prevalence of asthma.

Prophylactic feeding guidelines for the prevention of asthma and allergy have been established for the general population as well as for children at increased risk for asthma and allergy (usually describing children with a positive family history of asthma and allergy). These guidelines recommend exclusive breast feeding for the first 4-6 months with introduction of solids thereafter, egg, milk, and fish being added to the diet last. ${ }^{8-10}$ Recent WHO feeding guidelines propose the introduction of solids after the sixth month following exclusive breast feeding. ${ }^{11}$ Scientific evidence about the timing of solid food introduction is however scarce with research having mainly focused on the duration of breast feeding.

The aim of this investigation was to explore whether late introduction of solids is protective against the development of different wheezing phenotypes, atopy, and eczema in a population based prospective birth cohort. Furthermore we aimed to investigate whether there is evidence for a different role of feeding practices in relation to these outcomes depending on parental asthma and atopy status.

\section{METHODS}

\section{Study design}

The formation of this population based, prospective birth cohort study has been described elsewhere. ${ }^{12}$

Recruitment took place between November 1993 and July 1995. All pregnant women presenting in three general practices in Ashford, Kent (UK) were asked to participate in the study; 667 women (93\% of eligible mothers) agreed to take part, resulting in 642 live births. This analysis was based on follow up data to an age of $5 \frac{1}{2}$ years.

Data were collected by interviews using standardised questionnaires, and by skin prick tests. All data collection was carried out by three trained nurses. Ethical approval for the study was obtained from the hospital and from local ethics committees.

\section{Skin prick tests}

Parental and child's atopy status were determined by skin prick tests against common aero allergens (mixed grass pollen, cat fur, Dermatophagoides pteronyssinus; Allergopharma, Germany). Test results for 559 (87\% of the original cohort) fathers and 639 (99.5\% of the original cohort) mothers were available. Parental atopy status was considered positive if either of the parents showed a mean weal diameter of at least $3 \mathrm{~mm}$ greater than the negative control in any of the substances.

Children were skin prick tested at age $5 \frac{1}{2}$. Test results of 552 ( $86 \%$ of the original cohort) children were available. Child's atopy status was considered positive if a mean weal diameter at least $2 \mathrm{~mm}$ greater than the negative control was provoked by at least one of the substances. 


\section{Questionnaires}

Information on family history of asthma and allergy, mother's and child's health, sociodemographic factors, living and housing conditions, family details, and smoking was obtained by questionnaire during home visits twice within pregnancy, once when the child was 8 weeks old and yearly from 1 to 5 years of age. Mother's opinion of child's eczema and asthma status was obtained in the yearly questionnaires, along with breast feeding practices (exclusive breast feeding, exclusive bottle feeding, or both breast and bottle feeding) at age 8 weeks. The duration of breast feeding and first feeding of different food items was collected retrospectively at the year 1 interview.

Eczema $(n=214 / 604)$ was defined at age 5 years as an affirmative response to the question: "Has a doctor ever told you that your son/daughter has eczema?" This definition has shown good validity in comparison with GP records. ${ }^{12}$

The definitions for wheezing were based on the yearly questions on wheezing (in the absence of a cold or infection) in the preceding 12 months and were defined as follows:

- Preschool wheezing $(\mathrm{n}=114 / 604)$ :

- wheezing in year 5 and additionally in one of the preceding years or

- wheezing in each of the years 1 to 4 .

- Transient wheezing $(\mathrm{n}=185 / 606)$ :

- wheezing in any of the first two years but not in year 4 or 5 .

The exposure factors were derived from the first year questionnaire: "When did you start feeding your son/ daughter the following foods?" Food items considered in the questionnaire were fruits, vegetables, baby rice, cereal products, meat, fish, milk products, egg. A summary variable on solids was constructed, defining the first introduction of any of the above mentioned solids.

Variables a priori assumed to be potential confounders or risk factors of the outcomes were included in the analysis: sex, parental asthma, parental atopy, smoking in pregnancy, household smoking at age 51/2, mother's education (at least one year education after leaving school versus less than one year), breast feeding (ever/never), social class according to the UK Registrar General's classification of the paternal profession, ${ }^{13}$ number of rooms in the house, birth order, number of siblings at age $5 \frac{1}{2}$, birth weight, and maternal age at birth of first child.

Parental atopy and asthma were a priori defined potential effect modifiers.

\section{Statistical analysis}

\section{Descriptive analysis}

The distribution of characteristics of the population and of selected potential risk factors of the outcomes was compared for children with and without missing values on any of the outcome variables. The $\chi^{2}$ test and two-sample $t$ test were used where appropriate.

Data on the timing of first solid food intake were treated as quantitative variables within the first year of life, reporting medians and $90 \%$ centile ranges. For further analysis, exposure data were split into binary variables, on the one hand aiming to have similar group sizes, while on the other hand only using whole numbers as cut-offs. Children who had not yet eaten a certain food at year 1 were included in the group above median.

Principal component and logistic regression analysis Logistic regression was used to estimate crude odds ratios (OR) and their 95\% confidence intervals (CI) for the associations between the introduction of solids and preschool wheezing, transient wheezing, atopy, and eczema.

Due to the collinearity of the various food items, principal component analysis on the nutritional variables was carried out to characterise the underlying structure of the highly correlated data. On the basis of this analysis, nutritional variables were divided into three groups. Group 1 included: timing of the introduction of rice, meat, fruit, cereal, and vegetables. Group 2 included the timing of the introduction of fish, egg, and milk, while Group 3 included only having ever been breast fed. Nutritional factors with a $\mathrm{p}$ value below 0.2 in univariate analyses were included in the multivariate models. If more than one factor was significant in the same group in univariate analysis, the single factor that fitted the model best was included in the multivariate model.

Multivariate models were built for each outcome. All potential risk factors and a priori defined confounders were considered for inclusion. Factors were included one at a time. Factors were kept in the model if they were still significant at the $95 \%$ significance level or if they confounded the association between the exposure factors and the disease, causing an appreciable change in the main exposure estimates. Subsequently the final model for all four outcomes included all risk factors and confounding variables found relevant. Statistical significance of the associations was assessed by likelihood ratio tests (LRT). Tests for interaction were performed for variables that were a priori believed to be effect modifiers. All statistical analysis was performed with STATA 7.0 (Stata Corp., Texas, USA).

\section{RESULTS}

\section{Study population}

The original cohort contained 642 children. At age $51 / 2$ years, data were available for preschool wheezing 604 (94\%), transient wheezing 606 (94\%), atopy 552 (86\%), and eczema $604(94 \%)$.

The study population contained slightly more boys than girls (table 1). Approximately $25 \%$ of subjects had a positive family history of asthma, whereas the majority of children had at least one parent with a positive skin prick test. Smoking exposure increased from pregnancy $(19 \%$ of pregnant mothers were smoking) to the time when the children were $5 \frac{1}{2}$ years old $(36 \%$ of households with smoking).

Only birth weight was significantly higher in children with complete data on all outcome variables than in those without (table 1). Breast feeding was more common in the group of subjects with complete data on all outcome variables, but this difference did not reach statistical significance. There were no relevant differences in the introduction of solids between the two groups.

\section{Feeding practices}

Within the first year of life, rice, fruit, vegetables, and cereal were given earlier than meat, fish, and milk. Egg was fed latest with a median of 8 months (table 2). A substantial proportion of children had not had rice, fish, and egg before the age of 1 year. One per cent of the children were fed with rice and cereal within their first month of life.

Only 388 (62.3\%) children have ever been breast fed; 186 $(29.9 \%)$ children were exclusively breast fed until age 8 weeks.

\section{Prevalence of preschool wheezing, transient wheezing, atopy, and eczema in relation to the introduction of solids}

In the study population, preschool wheezing had a prevalence of $18.9 \%$, transient wheezing $30.5 \%$, atopy $16.7 \%$, and eczema $35.4 \%$ (table 3 ). 


\begin{tabular}{|c|c|c|c|}
\hline & $\begin{array}{l}\text { Outcomes data } \\
\text { complete, } n=551 \\
n(\%)\end{array}$ & $\begin{array}{l}\text { Missing outcomes } \\
\text { data, } \mathrm{n}=91 \\
\mathrm{n}(\%)\end{array}$ & p valuet \\
\hline Male gender $(n=641)$ & $294(53.4)$ & $49(54.4)$ & 0.85 \\
\hline Parental asthma $(n=638)$ & $137(25.0)$ & $25(27.8)$ & 0.58 \\
\hline Parental atopy $(n=576)$ & $320(63.0)$ & $46(67.7)$ & 0.45 \\
\hline Smoking in household at age $5 \frac{1}{2}(n=604)$ & $198(35.9)$ & $22(41.5)$ & 0.42 \\
\hline Mother's further education $(n=613)$ & $280(51.2)$ & $36(54.6)$ & 0.61 \\
\hline Maternal age at birth $(n=640)$ & $27.7(4.8)^{*}$ & $27.5(5.0)^{*}$ & 0.69 \\
\hline Birth weight in grams $(n=639)$ & $3407.0(566.5)^{*}$ & $3252.9(575.7)^{*}$ & 0.02 \\
\hline Birth order $(n=642)$ & & & 0.67 \\
\hline First & $233(42.3)$ & $37(40.7)$ & \\
\hline Second & $199(36.1)$ & $37(40.7)$ & \\
\hline Third to sixth & $119(21.6)$ & $17(18.7)$ & \\
\hline First feeding of solids after 3 rd month $(n=593)$ & $234(44.6)$ & $33(48.5)$ & 0.54 \\
\hline Ever breast fed $(n=623)$ & $347(63.0)$ & $41(56.9)$ & 0.32 \\
\hline \multicolumn{4}{|c|}{$\begin{array}{l}\mathrm{n} \text {, number of observations. } \\
{ }^{*} \text { Mean (standard deviation). } \\
t p \text { from } \chi^{2} \text { test for categorical variables and from two-sample } t \text { test for continuous variables. }\end{array}$} \\
\hline
\end{tabular}

Late introduction of egg and milk significantly increased the prevalence of eczema at age 5 years in unadjusted analysis. No other statistically significant associations were found between the feeding variables and any of the outcomes.

\section{Multivariate analysis regarding the introduction of solids and preschool wheezing, transient wheezing, atopy, and eczema}

The risk profile of the wheezing outcomes investigated in this analysis corresponded with the risk profile reported in the literature. Atopy of the child at age $5 \frac{1}{2}$ years, smoking in the household at age $51 / 2$ years, and parental history of asthma showed a highly significant positive association with preschool wheezing in multivariate analysis $(p \leqslant 0.001)$. For transient wheezing, no such association was found. On the contrary a significant inverse association between atopy and transient wheezing was observed $(\mathrm{p}<0.001)$.

According to the findings from principal component analysis and the significance levels from the univariate analyses, introduction of egg and vegetables as well as breast feeding were incorporated in the multivariate models (table 4). Late introduction of egg increased the relative risk of eczema (adjusted odds ratio (aOR) 1.6, 95\% CI 1.1 to 2.4) and preschool wheezing (aOR 1.5, 95\% CI 0.92 to 2.4 ). However, only the first association was significant. The odds ratio for the association between breast feeding and eczema

Table 2 Age of first nutritional factor intake and length of breast feeding

\begin{tabular}{|c|c|c|}
\hline & $\begin{array}{l}\text { Not yet eaten } \\
\text { by age } 1 \text { year } \\
\text { n (\%) }\end{array}$ & $\begin{array}{l}\text { Age of first intake (mth) } \\
\text { when eaten by age } \\
1 \text { year } \\
\text { Median } \\
\text { ( } 90 \% \text { central range) }\end{array}$ \\
\hline \multicolumn{3}{|l|}{ Type of nutritional factors } \\
\hline Rice $(n=623)$ & $60(9.6)$ & $3(1.4$ to 5.0$)$ \\
\hline Fruit $(n=623)$ & $2(0.3)$ & $4(2.3$ to 6.0$)$ \\
\hline Vegetables $(n=623)$ & - & $4(2.3$ to 6.0$)$ \\
\hline Cereal $(n=621)$ & $2(0.3)$ & $4(2.3$ to 7.0$)$ \\
\hline Meat $(n=623)$ & $19(3.0)$ & $5(3.0$ to 9.0$)$ \\
\hline Fish $(n=619)$ & $47(7.6)$ & $5(3.0$ to 10.0$)$ \\
\hline Milk $(n=622)$ & $14(2.3)$ & $6(3.0$ tol 1.0$)$ \\
\hline $\operatorname{Egg}(n=620)$ & $95(15.3)$ & $8(4.0$ to 11.0$)$ \\
\hline Breast fed $(n=388)$ & $37(9.5)^{*}$ & $3(0.2$ to 11.0$) \dagger$ \\
\hline
\end{tabular}

*Still breast fed at year 1

†Duration of breast feeding within the first year of life (in months). pointed in a protective direction. No other appreciable effect of the introduction of solids in relation to any of the outcomes was observed in these multivariate models. When substituting late introduction of egg by late introduction of milk in the respective models, a similarly significantly increased risk of eczema (aOR 1.7, 95\% CI 1.1 to 2.5 ) was observed.

Analyses were carried out on separate strata of parental allergy status, and tests for interaction were performed for mother's opinion on child's eczema status at year 1 as well as for parental allergy, asthma, and atopy status. There was no evidence of feeding practices playing a different role in the development of asthma and eczema with respect to these factors.

The analysis was repeated for exposure categorisations that have previously been applied by Fergusson and colleagues, including the number of nutritional factors given within the first four months (three categories: none, $1-3$ factors, $\geqslant 4$ factors). ${ }^{14}$ Furthermore, an exposure variable defining the first introduction of any of the solids was tested. In multivariate analyses, none of these exposure variables reached statistical significance. Additionally, no statistical significant association in multivariate analyses between exclusive breast feeding at age 8 weeks and any of the outcomes was found.

\section{DISCUSSION}

The results from this population based prospective birth cohort study on asthma and allergy provide no evidence for a substantial protective effect of late introduction of solids for the development of asthma and eczema. On the contrary, there was a statistically significant increased risk of eczema in relation to late introduction of egg (aOR 1.6, 95\% CI 1.1 to 2.4) and milk (aOR 1.7, 95\% CI 1.1 to 2.5). Late introduction of egg was furthermore associated with a non-significant increased risk of preschool wheezing (aOR 1.5, 95\% CI 0.92 to 2.4). There was no statistical evidence of feeding practices playing a different role in the development of asthma and eczema after stratification for parental asthma and atopy status.

Asthma is one of the most common diseases in childhood, causing substantial morbidity and considerable costs to the health care system. Although asthma generally manifests as wheezing, longitudinal studies have identified specific phenotypes over childhood years associated with different risk profiles and varying prognoses. Persistent and late onset wheezing, as defined by Martinez et al, are both seen as strong predictors for asthma in later life and share the main 
Table 3 Prevalence of preschool wheezing, transient wheezing, atopy, and eczema at age $5 \frac{1}{2}$ according to timing of introduction of solids and breast feeding response

\begin{tabular}{|c|c|c|c|c|c|c|c|c|}
\hline & $\begin{array}{l}\text { Preschool } \\
\text { wheezing } \\
(\%)\end{array}$ & p value* & $\begin{array}{l}\text { Transient } \\
\text { wheezing } \\
\text { (\%) }\end{array}$ & p value* & $\begin{array}{l}\text { Atopy } \\
\text { (\%) }\end{array}$ & p value* & $\begin{array}{l}\text { Eczema } \\
(\%)\end{array}$ & p value* \\
\hline Total $(n=642)$ & 18.9 & & 30.5 & & 16.7 & & 35.4 & \\
\hline \multicolumn{9}{|l|}{ Rice } \\
\hline$\leqslant 3 \mathrm{mth}(\mathrm{n}=308)$ & 16.9 & & 33.3 & & 14.6 & & 33.8 & \\
\hline$>3 \mathrm{mth}(\mathrm{n}=306)$ & 19.9 & 0.35 & 28.1 & 0.17 & 18.2 & 0.27 & 36.8 & 0.44 \\
\hline \multicolumn{9}{|l|}{ Fruit } \\
\hline$\leqslant 4 \mathrm{mth}(\mathrm{n}=442)$ & 18.5 & & 32.1 & & 16.3 & & 36.9 & \\
\hline$>4 \mathrm{mth}(\mathrm{n}=181)$ & 20.0 & 0.68 & 26.6 & 0.18 & 17.6 & 0.71 & 32.0 & 0.25 \\
\hline \multicolumn{9}{|l|}{ Vegetables } \\
\hline$\leqslant 4 \mathrm{mth}(\mathrm{n}=449)$ & 18.3 & & 32.3 & & 16.5 & & 36.2 & \\
\hline$>4 \mathrm{mth}(\mathrm{n}=174)$ & 20.7 & 0.50 & 25.7 & 0.11 & 17.0 & 0.90 & 33.7 & 0.57 \\
\hline \multicolumn{9}{|l|}{ Cereal } \\
\hline$\leqslant 4 \mathrm{mth}(\mathrm{n}=313)$ & 18.5 & & 29.7 & & 15.5 & & 37.6 & \\
\hline$>4 \mathrm{mth}(\mathrm{n}=308)$ & 19.3 & 0.80 & 31.1 & 0.70 & 18.0 & 0.45 & 33.3 & 0.28 \\
\hline \multicolumn{9}{|l|}{ Meat } \\
\hline$\leqslant 5 \mathrm{mth}(\mathrm{n}=365)$ & 19.3 & & 30.0 & & 15.2 & & 34.8 & \\
\hline$>5 \mathrm{mth}(\mathrm{n}=256)$ & 18.6 & 0.83 & 30.5 & 0.90 & 19.1 & 0.23 & 36.7 & 0.64 \\
\hline \multicolumn{9}{|l|}{ Fish } \\
\hline$\leqslant 6$ mth $(n=414)$ & 19.2 & & 31.3 & & 17.1 & & 35.2 & \\
\hline$>6 \mathrm{mth}(\mathrm{n}=200)$ & 17.4 & 0.59 & 28.6 & 0.49 & 14.8 & 0.49 & 35.7 & 0.90 \\
\hline \multicolumn{9}{|l|}{ Milk } \\
\hline$\leqslant 6 \mathrm{mth}(\mathrm{n}=407)$ & 18.8 & & 29.6 & & 16.9 & & 32.3 & \\
\hline$>6 \mathrm{mth}(\mathrm{n}=213)$ & 19.1 & 0.92 & 32.2 & 0.50 & 16.4 & 0.88 & 41.2 & 0.032 \\
\hline \multicolumn{9}{|l|}{ Egg } \\
\hline$\leqslant 8 \mathrm{mth}(\mathrm{n}=315)$ & 16.2 & & 29.0 & & 15.4 & & 30.5 & \\
\hline $8 \mathrm{mth}(\mathrm{n}=295)$ & 21.0 & 0.14 & 31.6 & 0.50 & 17.6 & 0.50 & 39.3 & 0.025 \\
\hline \multicolumn{9}{|l|}{ Solid foods } \\
\hline$\leqslant 3 \mathrm{mth}(\mathrm{n}=326)$ & 16.7 & & 31.6 & & 14.4 & & 34.4 & \\
\hline$>3 \mathrm{mth}(\mathrm{n}=267)$ & 19.2 & 0.45 & 28.6 & 0.44 & 18.8 & 0.17 & 35.0 & 0.88 \\
\hline \multicolumn{9}{|l|}{ Breast fed } \\
\hline Never $(n=235)$ & 22.1 & & 33.2 & & 13.2 & & 39.5 & \\
\hline Ever $(n=388)$ & 17.2 & 0.14 & 28.9 & 0.27 & 18.7 & 0.09 & 33.2 & 0.12 \\
\hline
\end{tabular}

risk factors. ${ }^{1}$ We combined them to one single outcome of preschool wheezing to increase the number of cases and the power of the study. Transient wheezing on the other hand is seen as an outcome unrelated to asthma in adult life. However, a large part of ever wheeze in childhood is attributable to transient wheeze. Even though our definitions of preschool and persistent wheezing were not exactly comparable with the wheezing outcomes applied by Martinez et al, they showed a similar risk profile.

Current feeding guidelines recommend delayed feeding of solids for the prevention of asthma and atopy, and follow the view that allergen avoidance leads to a reduction of asthma and allergy. This is thought to be mediated by sensitisation against food and subsequent inhalant allergens which have been found to be associated with asthma and allergy. ${ }^{67}$ The sensitisations are believed to result from early life exposure to these allergens.
However, when considering the different wheezing types, the hypothesis that late feeding of solids is protective against the development of asthma and atopic sensitisation against aero allergens was not supported by our results. These findings confirm reports of two earlier prospective birth cohorts that have found no association between the introduction of any solids and doctor diagnosed asthma at age 4 and 7 years $^{15}{ }^{16}$ and the results of an intervention study seeing no protective effect of a combined mother's and child's dietary intervention on allergic airways disease at the ages 1, 2, and 7 years. $^{6}$ Studies investigating the introduction of solids in relation to ever wheezing came to conflicting results. A statistically significant increase in ever wheezing within the first seven years of life in relation to late introduction of any solids has been reported by one of these studies. ${ }^{16}$ No such association was seen in another cohort study that followed the children until age 2

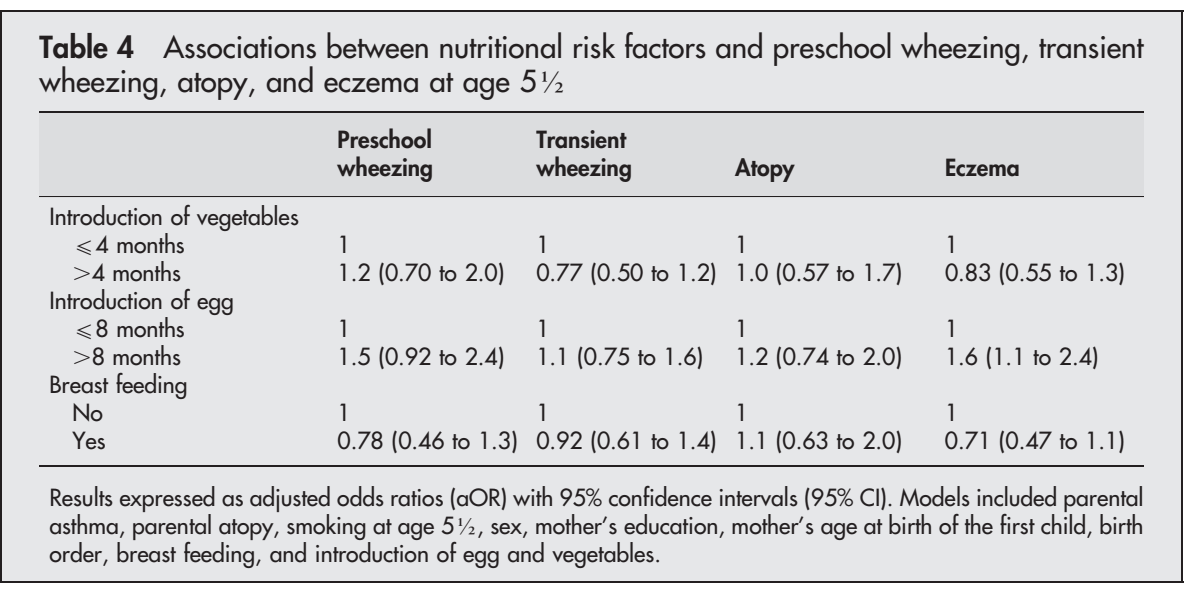


years. ${ }^{17}$ However, since a considerable part of ever wheezing is accounted for by transient wheezing, an increase in ever wheezing is unlikely to predict asthma in later life. None of these studies differentiated solids into single food items or investigated the different patterns of the introduction of solids.

We also did not find a protective relation between the late introduction of solids and atopic eczema. Conversely, Fergusson et al found a dose-response relation between the number of different food items given within the first four months and eczema within the first 10 years of life. ${ }^{14}$ Dietary diversity thereby seemed to be a stronger predictor for eczema than the presence of specific food items. Only an inconsistent relation between the introduction of any solids and eczema was found in a British study which followed the children for the first two years of life. ${ }^{17}$ Results from intervention studies suggest that feeding hydrolysed formulas is effective in the prevention of atopic dermatitis within the first year of life. ${ }^{6}{ }^{18}$ However, following the children up to age 7 years, no significant reduction of asthma, allergic rhinitis, atopic dermatitis, and sensitisation to food and aeroallergen in the intervention group in comparison to the control group was observed. ${ }^{6}$

We investigated the relation of specific solid food items, the categorisations applied by Fergusson et al, and the introduction of any solids in relation to transient wheezing, preschool wheezing, atopy, and atopic eczema. Neither breast feeding nor the introduction of solids had a significant protective effect in relation to any of the investigated outcomes, regardless of the respective categorisations. On the contrary we found a statistical significant increased risk for eczema (aOR 1.6, 95\% CI 1.1 to 2.4) and a non-significant increased risk for preschool wheezing (aOR 1.5, 95\% CI 0.92 to 2.4) in those children that have been fed egg later. Egg was part of the same group of principal components as milk and fish. Even though egg seemed to be the most important factor in univariate analysis in this group, milk showed a considerable effect in multivariate analysis as well (aOR 1.7, 95\% CI 1.1 to 2.5$)$.

Reverse causality in combination with residual confounding seems the most likely explanation for these associations. Since feeding guidelines recommend the late introduction of egg, milk, and fish for the prevention of asthma and allergy, affected parents or mothers believing that their child already developed eczema might delay feeding these foods. We therefore performed tests for interaction for parental asthma and allergy status as well as for mother's opinion of the child's eczema status at age 1 year. No significant interactions were found. Nevertheless, reverse causality is still a possible explanation of the positive association between late introduction of egg and eczema and preschool wheezing, since paediatricians may recommend late introduction of egg, fish, and milk based on knowledge of the atopy status of the extended family-that is, siblings, aunts, and cousins who were not assessed in this study.

According to the concept of gene environment interaction, solid feeding guidelines often recommend later introduction of solids for children with parental asthma and eczema. The data presented here gave no evidence that children with a positive family history were more likely to develop asthma or eczema when fed solids earlier as assessed by stratification on family history.

Other alternative explanations and limitations of the study design have to be considered in the interpretation of our results. Selection bias was not a major issue in this study. The study sample was drawn from the general population; participation in the study was high and losses to follow up small. Subjects with missing values on any of the outcome variables did not differ substantially from subjects with complete data (table 1). Only birth weight differed significantly between the two groups. However, this was not thought to reduce the validity of the results as birth weight was not a significant risk factor in our analysis.

Exposure was assessed retrospectively at age 1 year. Exposure misclassification could possibly have arisen by the retrospective assessment. Differential misclassification due to recall bias seemed unlikely because of the prospective character of the study with atopy, eczema, and preschool wheezing being defined after the exposure assessment. Nondifferential misclassification is more likely to have occurred due to possible imprecision of exposure measurement. However, we believe that as one year is a relatively short time period, parents' recall should be sufficiently precise to avoid substantial misclassification. Non-differential misclassification would result in an underestimation of the true effect. Also the relatively small sample size might result in non-significant results. Yet if one food item or the combination of different solid food items were a truly important risk factor for any of the outcomes, a substantial effect would most likely have been observed.

\section{Conclusions}

The results presented here do not support the recommendations given by the guidelines for the prevention of asthma and allergy in general populations stating that the introduction of solids should be delayed for at least 4-6 months. This is supported by findings from other negative studies suggesting that these guidelines are based on scarce scientific evidence. Not only is there doubt about the efficacy of late feeding of solids in infancy, recent findings from a large birth cohort in New Zealand suggest that breast feeding may likewise lack protective effects for the development of asthma and allergies. ${ }^{19}$ Therefore, paediatric guidelines for infant feeding practices with respect to the primary prevention of asthma and allergies may have to be revised.

\section{ACKNOWLEDGEMENTS}

Contribution to paper: A Zutavern: author and data analysis; E von Mutius and P Cullinan: co-authors; J Harris: data management; P Mills, S Moffatt, and C White: data collection.

\section{Authors' affiliations}

A Zutavern, E von Mutius, Dr von Haunersches Kinderspital (University Children's Hospital); Lindwurmstr. 4, 80337 Munich, Germany J Harris, P Mills, S Moffatt, C White, P Cullinan, Department of Occupational and Environmental Medicine, Imperial College of Science and Technology (National Heart and Lung Institute), Ib Manresa Road, London SW3 6LR,UK

The study was funded by the Colt foundation

\section{REFERENCES}

1 Martinez FD, Wright AL, Taussig LM, et al. Asthma and wheezing in the first six years of life. The Group Health Medical Associates. N Engl J Med 1995;332:133-8.

2 Martinez FD. Development of wheezing disorders and asthma in preschool children. Pediatrics 2002;109(2 suppl):362-7.

3 Peat JK, Salome CM, Woolcock AJ. Longitudinal changes in atopy during a 4year period: relation to bronchial hyperresponsiveness and respiratory symptoms in a population sample of Australian schoolchildren. J Allergy Clin Immunol 1990;85(1 pt 1):65-74.

4 Rhodes HL, Thomas P, Sporik R, et al. A birth cohort study of subjects at risk of atopy: twenty-two-year follow-up of wheeze and atopic status. Am J Respir Crit Care Med 2002;165:176-80.

5 Nickel R, Kulig M, Forster J, et al. Sensitization to hen's egg at the age of twelve months is predictive for allergic sensitization to common indoor and outdoor allergens at the age of three years. J Allergy Clin Immunol 1997;99:613-17

6 Zeiger RS, Heller S. The development and prediction of atopy in high-risk children: follow-up at age seven years in a prospective randomized study of combined maternal and infant food allergen avoidance. J Allergy Clin Immunol 1995;95: $1179-90$

7 Illi S, von Mutius E, Lau S, et al. The pattern of atopic sensitization is associated with the development of asthma in childhood. J Allergy Clin Immunol 2001;108:709-14. 
8 Statement of the Joint Working Group: Canadian Paediatric Society. Dieticians of Canada. Health Canada. Nutrition for Healthy Term Infants. 1998; Available from: http://www.hc-sc.gc.ca/hppb/ childhood-youth/cyfh/homepage/nutrition/intro.html. Accessed December, 2002.

9 DGKJ. Ernährung des Säuglings. In: Deutsche Gesellschaft für Kinderheilkunde und Jugendmedizin, ed. Leitlinien Kinderheilkunde und Jugendmedizin. München, Jena: Urban \& Fischer, 2002:D11-3.

10 Schweizerische Gesellsschaft für Paediatrie; Ernährungskommision. Empfehlungen fuer die Saeuglingsernaehrung 1998. BMS 1998;79:1143-56.

11 Anon. News in brief: WHO recommends exclusive breast feeding for first six months. BMJ 2001;322:1266.

12 Harris JM, Cullinan P, Williams $\mathrm{HC}$ et al. Environmental associations with eczema in early life. Br J Dermatol 2001;144:795-802.

13 Office of National Statistics. Standard Occupational Classification. London: HMSO, 1990.
14 Fergusson DM, Horwood $\sqcup$, Shannon FT. Early solid feeding and recurrent childhood eczema: a 10-year longitudinal study. Pediatrics 1990;86:541-6. 15 Fergusson DM, Horwood U, Shannon FT. Asthma and infant diet. Arch Dis Child 1983:58:48-51.

16 Wilson AC, Forsyth JS, Greene SA, et al. Relation of infant diet to childhood health: seven year follow up of cohort of children in Dundee infant feeding study. BMJ 1998;316:21-5

17 Forsyth JS, Ogston SA, Clark A, et al. Relation between early introduction of solid food to infants and their weight and illnesses during the first two years of life. BMJ 1993;306:1572-6.

18 von Berg A, Koletzko S, Grubl A, et al. The effect of hydrolyzed cow's milk formula for allergy prevention in the first year of life: the German Infant Nutritional Intervention Study, a randomized double-blind trial. J Allergy Clin Immunol 2003;111:533-40.

19 Sears MR, Greene JM, Willan AR, et al. Long-term relation between breastfeeding and development of atopy and asthma in children and young adults: a longitudinal study. Lancet 2002;360:901-7.

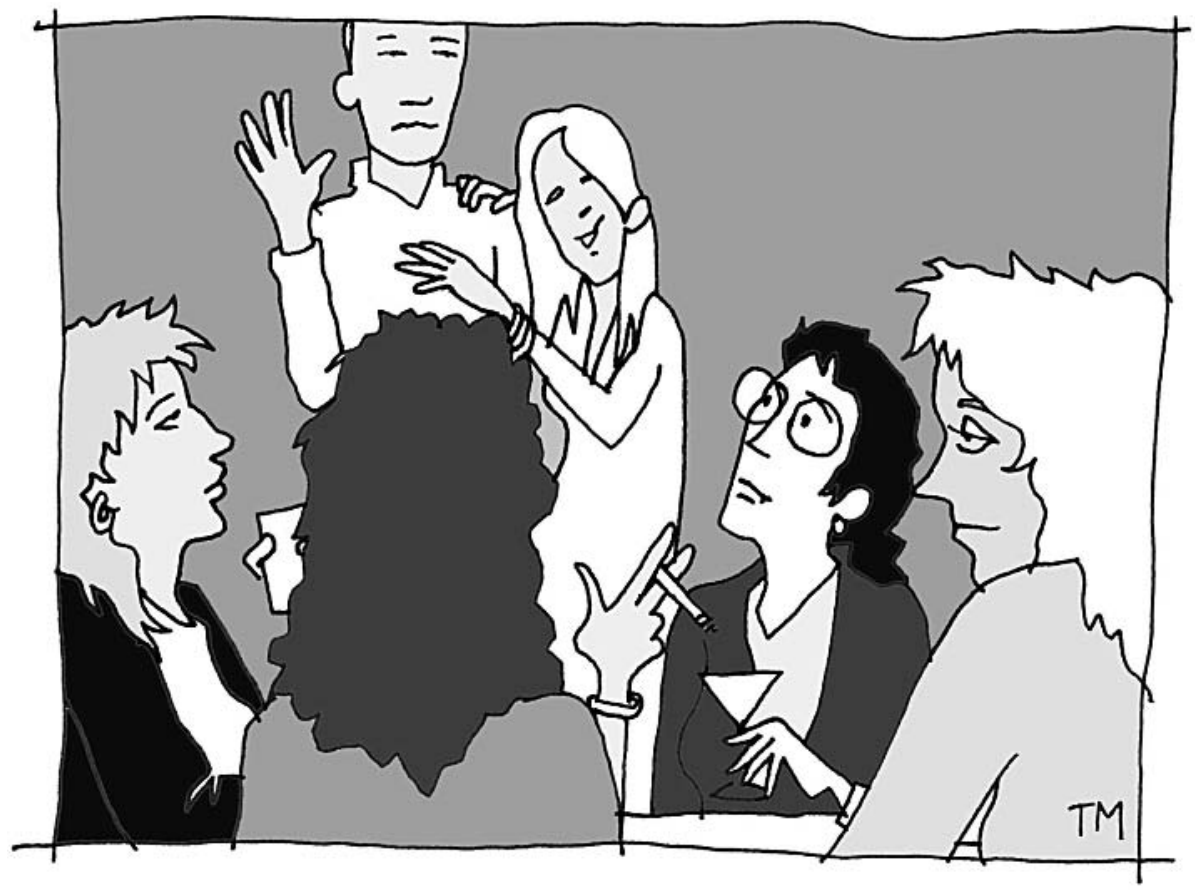

